\title{
Integral Biomathics Reloaded: 2015
}

\author{
Plamen L. Simeonov \\ JSRC \& Dahlem Centre for Genome Research and Medical Systems Biology, Berlin, Germany \\ Ron Cottam \\ The Living Systems Group (LIFE) \\ Department of Electronics and Informatics, Vrije Universiteit Brussel (VUB), Brussels, Belgium
}

\section{Recap and antrorse}

Many biological phenomena do not have adequate mathematical representations. This is because living systems use structures that are not yet grasped by our present conceptions of mathematics and computation. In particular they are circularly organized and they use recursions. Mathematics and computation at the present time deal only superficially with circular organization or the consequences of recursion. We just have not yet found a way to adequately deal with such matters ${ }^{1}$ !

Current approaches to complex problems rely on modelling, but one aspect of the problem is that they rely on a single form of mathematics, switching from it to another to address the next aspect, and so on. All this switching is an indication of how inadequate our mathematical tools are to date (ODE/PDE systems, stochastic models, discrete state-transition systems, topological algebra, etc.). Biological systems function at all these levels simultaneously. Yet, the real problem is that even the simplest recursions are beyond our capacity to analyse at the present time. It is not biology that is too messy to be modelled; it is our use of current mathematical paradigms that are not able to adequately address these biological problems (Root-Bernstein, $R$. S., 2012). These paradigms are keeping biology within the fixed boundaries of physics, the domain of nonliving matter. Despite being the most advanced mathematics-based natural sciences discipline, physics is currently experiencing its own crisis when trying to overcome the dichotomy between its major theories (Smolin, 2006) and remains not sufficiently developed to explain living systems. Is this a chance in disguise? We believe that further advances in the sciences - physical, biological, social - require new levels of integration across the domains. It is a commonplace to seek a "paradigm shift" (Kuhn, 1962) to advance the frontiers of a scientific domain. Such shift can also uplift the network of interdisciplinary connections among existing research areas. However, we are seeking more than a shift that advances the network of the complex dynamical system of knowledge. We seek to advance the nature of the links of this network by encouraging the development of mathematical and computational methods that will at once change the shapes of the nodes and the links, thus performing a simultaneous "quantum jump" in multiple disciplines, to enable a new integration and rationalization of knowledge: Integral Biomathics. The major implications of this new paradigm for reinventing and re-engineering mathematics and computation address the life sciences and medicine. They encompass meanwhile also the foundations of creativity and cognitive processes in the sciences and the arts, as well as the phenomenology of consciousness in general.

\footnotetext{
${ }^{1}$ Recursion and computation are well defined concepts in arithmetic and set theory. The problem addressed here is related to the physical implementation of recursion (and to the question what is physics, which opens another discussion outside the scope of this paper). Louis Kauffman's favorite example of a deep recursion - that can only illustrate how complex could be the relationship between phenome features and inherited genome mutations in the course of evolution - is the Collatz Recursion:

$\mathrm{N}=\{0,1,2,3, \ldots\}=$ Natural numbers plus zero.

$\mathrm{F}: \mathrm{N} \longrightarrow \mathrm{N}$ defined by

$\mathrm{F}(\mathrm{n})=\mathrm{n} / 2$ if $\mathrm{n}$ is even,

$F(n)=3 n+1$ if $n$ is odd.

Start with any $n$ and iterate $F: n, F(n), F(F(n)), \ldots$

Conjecture: The sequence will eventually hit 0 . This is unproved.

The conjecture has been with us since the 1940's. There is no solution in sight yet. But Fermat's last theorem has been also with us for around 300 years until it was proved not long ago. So, the only limitations we know are of the form: "If you restrict discussion to a particular language L, then there will be results that cannot be explained within L." (corollary from Gödel's theorem). When mathematicians generate very difficult to understand recursions they are using the simple language of elementary mathematics to create abstractions that are not so easy to explain with that simple language. Then they are asked to become empiricists like Laplace and see what happens (Root-Bernstein, 2012) in the temporality of the recursion. Then (these) scientists can begin developing/ inventing a more sophisticated language for describing these phenomena. But these new nested levels of organization are not going to be simple axiomatics. They are going to appear much more like observational science. This is exactly the way in which Andrée Ehresmann and Jean Paul Vanbremeersch have developed (and still develop) Memory Evolutive Systems out from category theory (Ehresmann and Vanbremeersch, 2007).
} 
Integral Biomathics involves reconceptualising what mathematics is and its role in science, granting a place to, while clarifying, the relationship between the non-mathematical concepts of philosophical biology (Sober, 2000; Griffiths, 2002; Godfrey-Smith, 2014), qualitative mathematics (Smith, 1983; Sacks, 1985; Rudolph, 2014) that provides insight but no precise predictions, analogical computation (Damper, 2001; Kokinov and French, 2002; Gentner and Forbus, 2011) and formal models that do facilitate precise predictions. In particular, philosophical biology and philosophical anthropology are far more than descriptive and concerned with justifying the reality of life and living beings, thereby revealing how misguided are efforts to examine these only in terms of received mathematical ideas. These disciplines are indeed in a dialectic relationship with 'mathematics for biomathics' (Hoffman, 2013), making their own distinctive contribution but needing to be contextualized. To engage the individual disciplines with each other is the goal of Integral Biomathics. However, we should be aware that interdisciplinarity and transdisciplinarity are not enough. We have to recognise that systems can be simply defined and evolve easily, but that they are not going to be analysable at the level of the languages and descriptions at which we have produced or begun to describe them (Gödel's insight). In fact, we are not dealing with the limitations of mathematics per se. We are dealing with an endless helix of creation, a Vitruvian Evolution of evolving and interpenetrating cognitive perspectives. When we look closely at what structures can be described or generated at a given level, new structures are enfolded and revealed like in a fractal image. These need new explorations and new levels of description, and hence imply new cycles of knowledge integration. Essentially this process comprises the search for better descriptions of living systems leading to the comprehension of their specific characteristics, including emergent properties all the way up to the higher order cognitive processes. What remains is to explain how this integration of multiple approaches is going to be realized in order to deliver new results and new insights about living systems.

Such a dramatic paradigm change in science has been attempted several times over the past sixty years by outstanding researchers. Now we venture to achieve the dreams of those pioneers by linking together their successors, backed by the wisdom of these forerunners. Our goal is to accelerate scientific development in the life sciences and personalized medicine through profoundly new theoretical foundations. In this quest we pursue a unified view of life that goes over scales. Until now, any attempt to deal with multi-scales using conventional techniques has been doomed to failure no matter how much data we collect. The problem is with their interpretation. One cannot go between adjacent scales in a real existing hierarchy by using the logic of either of the scales - the intermediate region is multiply fractal (Cottam et al., 2004a)! Local solutions require global knowledge (Cottam et al., 2013), but mathematics, not data, remains the key to biology. We need a return to the style of doing science in the 1970s (Justman, 2015) following bold approaches of the founders of bio-mathematics such as D'Arcy Wentworth Thompson, Alan Turing, John von Neumann, Nicolas Rashevsky, René Thom, Brian Goodwin, Conrad Hal Waddington, Michael Conrad and Robert Rosen enriched by the findings of theoretical and philosophical biologists from von Uexküll and Lorenz to Hoffmeyer and Kull. We call this new initiative for high-risk and high-impact research in Integral Biomathics SALVE: Support Action for Living Vitruvian Evolution to celebrate the multifaceted integrative da Vinci approach to science, engineering and the humanities. This project puts in place a cyclic discourse methodology stimulating the creation and alternation of innovative ideas for a scalable biological mathematics and computation and its validation in modelling real-life problems. The initiative organizes currently 84 experienced and enthusiastic scientists from a multidisciplinary worldwide community.

\section{Research Focus (RF): Second-Order and Higher-Order Logics Mapping Self-Organized Criticalities}

Reductionism reached its zenith in the third quarter of the XXth Century with the synthetic theory of evolution embracing molecular biology, cybernetics and information theory. Evolution was equated with changes in populations of genes, identified with DNA, encoding information on how to produce survival machines to reproduce themselves. Biology was reduced to chemistry, which was assumed to be explained by physics. Today theoretical biologists are intensifying their efforts to overcome reductionism in order to comprehend the reality of life. The research framework we focus on is not about developing models and engineering systems mimicking Nature based on conventional theories and automation. It is not about bioinformatics or biocomputation, understood as cellular/molecular/biochemical/DNA computing, either. The objective of a biology-driven mathematics pursued by Integral Biomathics is indeed an appraisal of the second-order types of nested logic in place of the first-order logic with which most standard mathematicians are familiar. 
This kind of "implicate order" (Bohm, 1980) should be also capable of capturing acategorical elements and other phenomenological aspects (Rosen, 2015), such as the dualistic ('endo' and 'exo') nature of time (see 3.4, KT4), which cannot be registered systematically, but only systatically. The great advantage of second-order logic over first-order is within its systatic capacity. One drawback of second-order logic is, however, that it is not decidable. Because of this weakness, most standard mathematicians still like to adhere to first-order logic, which is decidable or provable. How to make it decidable is a big issue for biology (and physics). In order to specify meaningful statements framed in second-order logic, some sort of qualifier needs to be used. Information, as a natural phenomenon of a layered, filtered and shared content (syntax, semantics, semiotics) is a crucial factor for making second-order logic - that is inevitably isolated on theoretical grounds decidable, as revealed in the origins of life. The central point here is that the phenomenology of information is intrinsically decidable if the internalist stance (Matsuno, 1996; 2013) - that of the first person observerparticipant (Vrobel, 2015) - is adopted. This includes the immanent decidability of complex biology-based information structures (Hankey, 2014). Our approaches target the realisation of homomorphisms within the synergetic bundle of i) higher-order multi-state switching logics (Goranson and Cardier, 2013), ii) memory evolutive systems (Ehresmann and Vanbremeersch, 2007), iii) wandering logic intelligence (Simeonov, 2002), and iv) self-organised criticalities (Hankey, 2015) in living systems. They are phenomenology-based (e.g. Simeonov, 2015; Matsuno, 2015; Hipólito, 2015; Ehresmann \& Gomez-Ramirez, 2015; Goranson et al., 2015) and bio/cyber-semiotics-based (Kull, 2015; Brier; 2015; Nakajima, 2015).

Indeed, much of the problem when trying to adequately represent the organization of living systems is in the arena of undecidability. We need to proceed with real examples and see what can happen. Sometimes we have to work without formal models for a long time in order to find the groundings. A good example of this is the work of Humberto Maturana who understands that human communication occurs at the level of coordinations of coordinations of actions (a second order logic), and we do not have perspicuous formalisms yet for the handling of this other than 'ordinary language', which in its performance IS such coordination of coordinations. Yet to realize the fine-tuned scheme of such helicoid evolving modelling relations for science (Fig. 1) we need to deploy another kind of squinted perceptive-narrative logic recognizing the 'difference that makes the difference' that assigns a meaning to the overall process in the words of Gregory Bateson.

P.L. Simeonov / Progress in Biophysics and Molecular Biology 102 (2010) 85-121

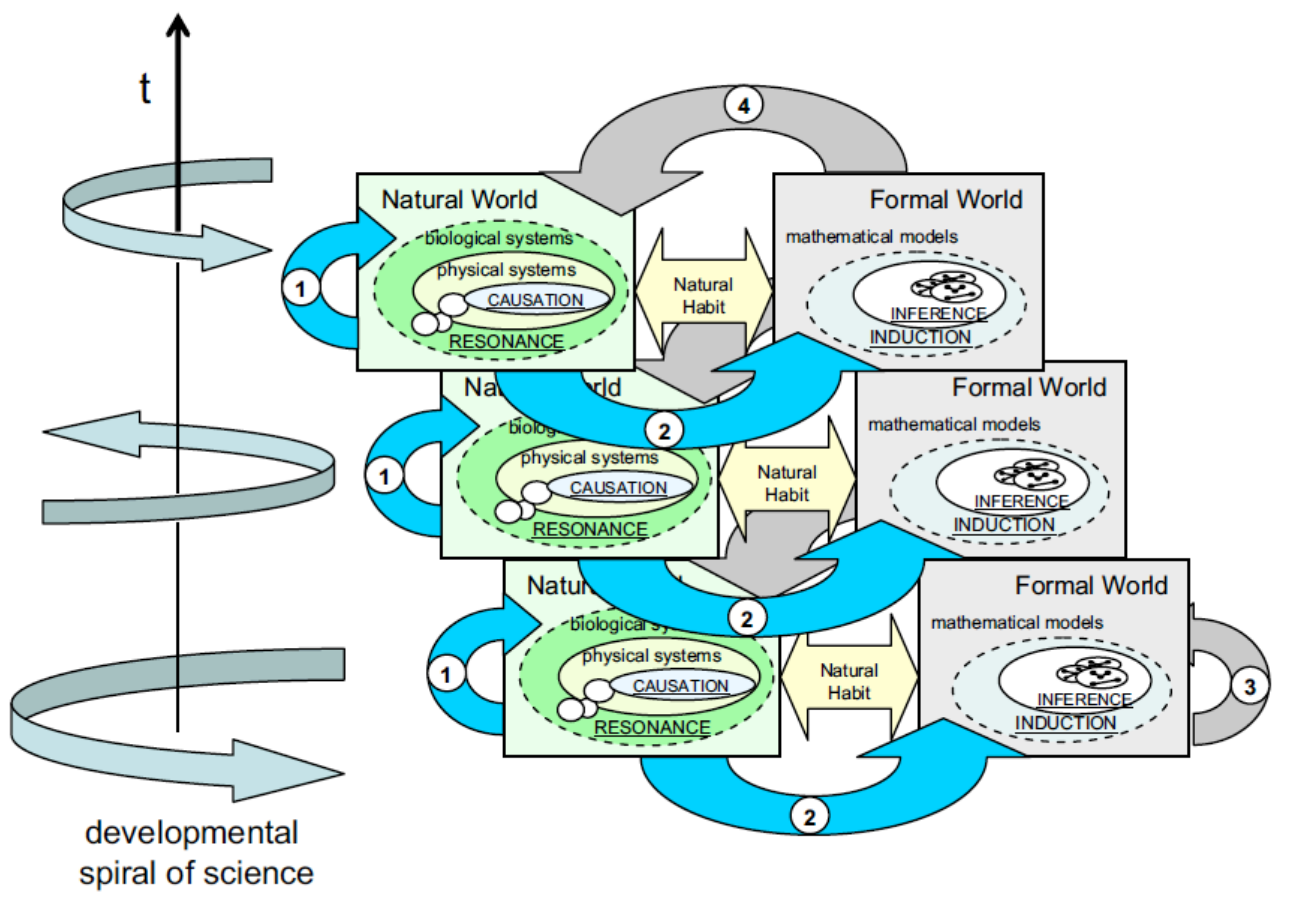

Fig 1. The evolving modelling relation for science (Simeonov, 2010)

${ }^{2}$ when related to combination or synthesis (systatics) 


\section{New Key Themes for Future Research}

The following new Key Themes (KT) have been identified and added to our Integral Biomathics research programme (Simeonov et al., 2012; Gare, 2013; Kauffman and Gare, 2015) in the course of the JPBMB publication activities in 2013 and 2015 (Simeonov et al, 2013; Simeonov et al, 2015).

\subsection{KT1: Two-sorted and multivalent logic}

Structural modelling of complex biological systems relies on formalisms inherited from physics. These formalisms scale poorly when dealing with interactions involving many variables and agents operating in multi-causal biosystems that cohere at multiple overlapping layers over multiple contexts. A two-sorted logic supplements the existing formalisms to mitigate these challenges (Goranson and Cardier, 2013). The purpose of this second logic is to track how multiple contexts relate to each other, as well as to the dependent structures they inform: a situating of situations. Supervenience (Davidson, 1970; Kim 1984; 1987) could be possibly addressed with two-sorted logic. This allows for capturing the multi-layered and multi-system dynamics that have been elusive in modelling emergent systems so far. The net of co-regulators in MES (Ehresmann \& Vandbremeersh, 2007) realizes a multivalent logic. Future multivalent logic models will require phenome ontologies and new kinds of abstractions to reason about interactions among contexts (as situations) as well as about facts. This advancement of current approaches will require basic research in type theory deploying phenomenological constructs for addressing the overlapping domains (Goranson et al., 2015). Of course, this focus can be only the beginning of a research on the adequate representations of dynamic structures and processes in living systems. Possible next steps could involve the investigation of the applicability of Grottendieck's extensions of abelian categories (MacLane, 1950; Murfet, 2006) for homological algebra (Grothendieck, 1957), his Topos Theory (Grothendieck, 1971; Artin et al., 1972) and other developments on this base (Lurie, 2009).

\subsection{KT2: Extended and Self-Organized Criticalities}

The analysis of criticality states is at the heart of regulation of complex biological systems (Thom, 1977; Rossi, 2011). A particularly interesting and relevant starting point for further investigations is related to the works on extended criticality and symmetry breakings (Longo \& Montévil, 2011; Longo, Montévil \& Kauffman, 2012), on self-organized criticality (Hankey, 2015) and on applying category theory to model living beings as close to criticality rhythmic pulsations between aspects of qualia and quanta (Cazalis, 2015). Criticality implies that the natural form of information processing at the loci of control of biological systems is neither digital nor limited by binary logic of the category of sets. Rather it involves singularity-based transformations hitherto studied in applications of renormalization group processes to complex critical phenomena (Vvedensky and Chang 1982, Chang e al., 1992). Such transformations can be shown to be relevant to elementary processing of information in all criticality based decision making processes in biology, from complex single cell behaviour (Ford, 2010), up to human information processing by manipulation of gestalts, as envisioned in (Hankey, 2015).

\subsection{KT3: Hierarchy and Heterarchy}

Life is hierarchically structured with complementary heterarchical (von Goldammer et al., 2003) inclusions (Cottam et al., 2005). In the brain, for example, massive information processing appears to tend towards heterarchical structures and processes, while reduction from heterarchy resulting in the sequential control of action is through hierarchical compression. But any attempt to deal with hierarchical multi-scales using conventional techniques is doomed to failure no matter how much data we collect. Generalization in a reductive world results in a small number of precise components, for example the array of physical laws. Generalization in a hierarchical living world, however, results in extreme vagueness. This makes the application of conventional mathematics to an overall view of life extremely difficult. Realizing that the one constraint on science, as on all thought, is (conventional) logic, then if we wish to go beyond it, the only possibility at present is to address vagueness, not algorithms. A possible approach to address this is the 'logic of vagueness" (Peirce, 1869; McCulloch, 1945; Brock, 1969, 1979). In addition, life is characterized by temporal evolution, whereas conventional mathematical equations are static and partially irreversible (see the example of $1+1=2$ in Cottam et al., 2004b). 


\subsection{KT4: Biological and Phenomenological Temporality}

The internalist manifestations of time in biology as a process awareness of internal and external changes (Matsuno, 1998; Matsuno and Salthe, 2002; Matsuno, 2012) and as time-consciousness (Husserl, 1991; Heidegger, 1996; Varela, 1999; Kortooms, 2002; Vrobel, 2013; 2015) are characteristic for living systems. "Time is obviously a phenomenon at the interface between (human) mind and the physical world." (Simeonov, 2015). Therefore this is going to be another key theme for the Integral Biomathics programme in future.

\subsection{KT5: Naturalistic Computation}

Many biological phenomena do not have adequate mathematical representations. This is because living systems are deploying logic and semiotics beyond our conception of mathematics into the domain of computation, which is on its part much richer than the standard Turing machine paradigm. Hypercomputation has probably the best chances today to develop into a form of naturalistic/naturalized computation, i.e. information processing based on its realization in living systems (Simeonov, 2010; Schroeder, 2013a/b; Schroeder, 2014). This is one of the greatest challenges, but also best opportunity in computation theory. Therefore, the results of KT1, KT2, KT3 and KT4 can directly flow into the SALVE research track on naturalizing computation. The most important goal of KT5 is to investigate the opportunities of a Turing Oracle Machine (TOM) implementation and two-sorted logic (KT1), capable of delivering complementary first and third person system descriptions ${ }^{3,}$ incl. their hierarchy/heterarchy (KT3) and temporality (KT4), thus bridging the gap between the formal and informal/narrative/visual modelling systems. Of course, such a system description addressing a challenging question like understanding the movements of viruses within the host organism (Zaichick et al., 2013) also implies a context (Kitto and Kortschak, 2013). The latter needs to be considered from a much broader perspective ${ }^{4}$ (Gabora et al., 2013; Gare, 2013) of interest for further research.

\subsection{KT6: AI \& Advanced Visual Analytics}

A good example of the significance of our proposal for the biomathematics of the future is the recent upheaval of weak artificial intelligence in almost any field of life today after decades of stagnation and deadlocks (Bostrom, 2014). Also, advanced data visualization techniques (Mazza, 2009; Signer et al., 2011; Zhang et al., 2011; Dill et al., 2012; Ware, 2013) often provide the key of the qualifier to decrypt ambiguous second order logic in biological phenomena such as the recognition and learning of cancer cells in virtual microscopy with the help of human experts in observation as practiced in digital pathology (Randell et al., 2014; Higgins, 2015). We regard advanced visual representation and analytics as adequate supplements to formal machineries of mathematics and computation. All the other key themes of KT1-KT5 are going to be addressed in KT6.

\section{Outlook}

There are basically two guideline themes motivating the relevancy of Integral Biomathics for science:

1. internal modellng problems in biology due, in part, to circularity and recursion, and

2. a need for wider and more sensitive interdisciplinary work.

They are separate but related parts of a whole that needs further exploration. A specific research goal of the SALVE project will be the creation of an exemplary model comprising a strategy to address these themes and exhibiting some of the proposed new key themes for research in this context. As a first practical step towards the realization of this vision, we propose to devise a moderate, but integrative and extensible methodology. This includes the development of a unified research framework in biomathematics and biocomputation to explore the relationship between morphogenesis and the development, evolution and degeneration of brain functions across multiple layers, domains and perspectives. This focus is interesting for investigation because networks of neurons are known to mimic arbitrarily complex catastrophes (Thom, 1977). Therefore, they must be uniquely qualified to model and control genetic networks (Hankey, 2014, p.245), which contain critical instabilities and operate at 'The Edge of Chaos' (Kauffman, 1996). If we succeed in testing this hypothesis in silico, then a holistic approach to treating neuroblastoma and cancer in general might be derived.

\footnotetext{
3 agent-based simulations could be held to be first person.

${ }^{4}$ incl. evolution, ecology, society and the researcher engaging in scientific inquiry, theorizing, measuring and communicating results as part of the context being investigated
} 


\section{Acknowledgements}

We dedicate this review article to our close ones, who had sufficient patience with our passion while we were preparing this project: Rossen and Rossitza (for Plamen) and Anne-Françoise (for Ron). Our special thanks go to Andrée Ehresmann, Arran Gare, Ralph Abraham, Bruno Marchal, Ted Goranson, Louis H. Kauffman, Lesley Ogilvie, Stuart A. Kauffman, Koichiro Matsuno and Alex Hankey for their valuable feedback.

\section{References}

Artin, M. Grothendieck, A., Verlier, J.L. 1972. Theorie des Topos et Cohomologie Étale des Schemas, Tome 1, Théorie des Topos (SGA4). Séminaire de Géométrie Algébrique du Bois-Marie (1963-1964). $2^{\text {nd }}$ edition. LNM. Springer. vols. 269, 270 and 305. MR 50/7130-2.

Bohm, D. 1980. Wholeness and the Implicate Order, Routledge, Reprint $2002 \quad$ ISBN-10: $\quad 0415289793$; ISBN-13: 978-0415289795.

Bostrom, N. 2014. Superintelligence: Paths, Dangers, Strategies. Oxford University Press. ISBN-10: 0199678111; ISBN-13: 978-0199678112.

Brier, S. 2015. Finding an information concept suited for a universal theory of information? J. Prog. Biophys Mol Bio. 119(2). Special Theme Issue on Integral Biomathics: Life Sciences, Mathematics, and Phenomenological Philosophy. Elsevier. ISSN: 0079-6107. (in print)

Brock, J., 1969. Peirce's Logic of Vagueness. Ph.D. dissertation. University of Illinois at Urbana-Champaign.

Brock, J., 1979. Principal themes in Peirce's logic of vagueness. In: Ketner, K.L., Ransdell, J.M. (Eds.), Studies in Peirce's Semeiotics. Peirce Studies, 1. A Symposium by Members of the Institute for Studies in Pragmaticism, Lubbock, Texas, pp. 41-49.

Cazalis, R. 2015. From creativity to perception: The conditions of possibility for a true biology. J. Prog. Biophys Mol Bio, 119(2). Special Theme Issue on Integral Biomathics: Life Sciences, Mathematics, and Phenomenological Philosophy. Elsevier. ISSN: 0079-6107.

Chang, T.S. Vvedensky, D.D., Nicoll, J.F. 1992. Differential renormalization-group generators for static and dynamic critical phenomena. Phys. Rep. 217(6): 279-360. Elsevier. doi:10.1016/0370-1573(92)90041W.

Cottam, R., Ranson, W., Vounckx. R. 2005. Life and simple systems. Sys Res Behav Sci 22:413-430.

Cottam, R., Ranson, W., Vounckx. R 2004a. Autocreative hierarchy I: structure - ecosystemic dependence and autonomy. SEED J. 4: 24-41.

Cottam, R., Ranson, W., Vounckx. R 2004b. Diffuse rationality in complex systems. In: Bar-Yam, Y., Minai, A. (eds.) Unifying Themes in Complex Systems, vol. II, 355-362. Westview Press, Boulder CO.

Cottam, R., Ranson, W., Vounckx. R 2013. A framework for computing like Nature," in: G. Dodig-Crnkovic and R. Giovagnoli, Eds., Computing Nature (Springer SAPERE series), pp. 23-60.

Damper, R. I. 2001. Analogical Reasoning, Analog Computation and the Computational Hypothesis of Cognitive Science. Conference on Model-Based Reasoning (MBR'01), May 17-19, 2001, Pavia, Italy. http://eprints.soton.ac.uk/255924/2/abst.pdf.

Davidson, D. 1970. Mental Events. In: L. Foster and J. W. Swanson (eds.), Experience and Theory, Duckworth; reprint in D.D. 2001. Essays on Actions and Events, Oxford Univ. Press.

Dill, J., Earnshaw, R., _Kasik, D., Vince, J., Wong, P. C. (Eds). 2012. Expanding the Frontiers of Visual Analytics and Visualization. Springer. ISBN 978-1-4471-2803-8.

Ehresmann, A.C., Gomez-Ramirez, J. 2015. Conciliating neuroscience and phenomenology via category theory. J. Prog. Biophys Mol Bio. 119(2). Special Theme Issue on Integral Biomathics: Life Sciences, Mathematics, and Phenomenological Philosophy. Elsevier. ISSN: 0079-6107. (in print)

Ehresmann, A. C., Vanbremeersch, J. P. 2007. Memory Evolutive Systems; Hierarchy, Emergence, Cognition. Elsevier Science. ISBN-10: 0444522441; ISBN-13: 978-0444522443.

Ford, B.J. 2010. The secret power of the single cell. New Scientist, 206(2757): 26-27. doi:10.1016/S02624079(10)61011-1.

Gabora, L., Scott, E. O., Kauffman, S. 2013. A quantum model of exaptation: Incorporating potentiality into evolutionary theory. J. Prog. Biophys Mol Bio. 113(1): 108-116. Special Theme Issue: Can biology create a profoundly new mathematics? ISSN: 0079-6107.

http://dx.doi.org/10.1016/j.pbiomolbio.2013.03.012. 
Gare, A. 2013. Overcoming the Newtonian paradigm: The unfinished project of theoretical biology from a Schellingian perspective. J. Prog. Biophys Mol Bio, 113(1): 5-24. Special Theme Issue on Integral Biomathics: Can Biology Create a Profoundly New Mathematics and Computation? Elsevier. ISSN: 0079-6107.

Gentner, D., Forbus, K. D. 2011. Computational models of analogy. Wiley Interdisciplinary Reviews: Cognitive Science, 2(3), 266-276.

http://groups.psych.northwestern.edu/gentner/papers/gentner\&Forbus 2011.pdf

Godfrey-Smith, P. 2014. Philosophy of Biology. Princeton University Press. ISBN: 9780691140018.

Goranson, T., Cardier, B. Devlin, K. 2015. Pragmatic Phenomenological Types. J. Prog. Biophys Mol Bio, 119 (2). Special Theme Issue on Integral Biomathics: Life Sciences, Mathematics, and Phenomenological Philosophy. Elsevier. ISSN: 0079-6107 (in print)

Goranson, H. T., Cardier, B. 2013. A Two-sorted Logic for Structurally Modeling Systems. J. Prog. Biophys Mol Bio, 113 (1): 141-178. Special Theme Issue on Integral Biomathics: Can Biology Create a Profoundly New Mathematics and Computation? Elsevier. ISSN: 0079-6107.

Griffiths, P. E. 2002. Philosophy of Biology. http://paul.representinggenes.org/webpdfs/Grif.06.PhilBiol.pdf.

Grothendieck, A. 1971. Revêtments Étales et Groupe Fondamental (SGA-1). Séminaire de Géométrie Algébrique du Bois-Marie (1960-1961). Springer LNM 224. Springer. ISBN: 978-3-540-05614-0. Update 2004: http://arxiv.org/pdf/math/0206203v2.pdf.

Grothendieck, A. 1957. Sur quelques points d'algèbre homologique, I. Tohoku Math. J. 9(2):119-221. doi:10.2748/tmj/1178244839. http://projecteuclid.org/euclid.tmj/1178244839.

Hankey, A. 2015. A Complexity Basis for Phenomenology: how information states at criticality offer a new approach to understanding experience of self, being and time. J. Prog. Biophys Mol Bio, 119(2). Special Theme Issue on Integral Biomathics: Life Sciences, Mathematics, and Phenomenological Philosophy. Elsevier. ISSN: 0079-6107. (in print)

Hankey, A. 2014. Complexity biology-based information structures can explain subjectivity, objective reduction of wave packets, and non-computability. Cosmos and History: The Journal of Natural and Social Philosophy, 10(1): 237-250. ISSN 1832-9101.

http://cosmosandhistory.org/index.php/journal/article/viewFile/417/752.

Heidegger, M. 1969. Zeit und Sein. In: Zur Sache des Denkens First Edtion. Niemeyer, Tübingen Germany, 125. also in: Heidegger, M. 1972. Being and Time. SUNY Press. ISBN-10: 0-7914-2677-7; ISBN-13: 978-0-7914-2677-7.

Higgins, C. 2015. Applications and challenges of digital pathology and whole slide imaging. Biotech Histochem. 90(5):341-7. doi: 10.3109/10520295.2015.1044566.

Hipólito, I. 2015. Proof phenomenon as a function of the phenomenology of proving. J. Prog. Biophys Mol Bio. 119(2). Special Theme Issue on Integral Biomathics: Life Sciences, Mathematics, and Phenomenological Philosophy. Elsevier. ISSN: 0079-6107. (in print)

Hoffman, W. C. 2013. Mathematics for Biomathics. J. Prog. Biophys Mol Bio, 113(1): 179-180. Special Theme Issue on Integral Biomathics: Can Biology Create a Profoundly New Mathematics and Computation? Elsevier. ISSN: 0079-6107.

Husserl, E. 1991. On the Phenomenology of the Consciousness of Internal Time (1893-1917). Trans. J. Brough. Collected Works IV. Dordrecht: Kluwer Academic Publishers. ISBN 0-7923-0891-3.

Justman, Q. 2015. 1970s Nostalgia for the Modern Day. Cell Systems. 1(3): 175. DOI: http://dx.doi.org/10.1016/j.cels.2015.09.003.

Kauffman, S.A., Gare, A. 2015. Beyond Descartes and Newton: Recovering life and humanity. J. Prog. Biophys Mol Bio. 119(2). Special Theme Issue on Integral Biomathics: Life Sciences, Mathematics, and Phenomenological Philosophy. Elsevier. ISSN: 0079-6107. (in print)

Kauffman, S.A. 1996. At Home in the Universe. The search for the laws of self-organization and complexity. Oxford University Press, Oxford. ISBN-10: 0195111303; ISBN-13: 978-0195111309.

Kim, J. 1987. 'Strong' and 'Global' Supervenience Revisited. Philosophy and Phenomenological Research, 48, 2: 315-326.

Kim, J. 1984. Concepts of Supervenience. Philosophy and Phenomenological Research ,45, 2: 153-176.

Kitto, K., Kortschak, R. D., 2013. Contextual models and the non-Newtonian paradigm. J. Prog. Biophys Mol Bio. 113(1): 97-107. Special Theme Issue on Integral Biomathics: Can Biology Create a Profoundly New Mathematics and Computation? Elsevier. ISSN: 0079-6107. 
Kokinov, B., French, R., M. 2002. Computational Models of Analogy Making. In: Lynn Nadel (ed.) Encyclopedia of Cognitive Science. MacMillan.

http://old.nbu.bg/cogs/personal/kokinov/ENCYCL98.PDF.

Kortooms, T. 2002. Phenomenology of Time. Edmund Husserl's Analysis of Time-Consciousness. Springer. ISBN 978-90-481-5867-6.

Kuhn, T. 1962. The Structure of Scientific Revolutions. University of Chicago Press. ISBN: 9780226458113.

Kull, K. 2015. Semiosis stems from logical incompatibility in organic nature: Why biophysics does not see meaning, while biosemiotics does. J. Prog. Biophys Mol Bio. 119(2). Special Theme Issue on Integral Biomathics: Life Sciences, Mathematics, and Phenomenological Philosophy. Elsevier. ISSN: 00796107. (in print)

Longo, G., Montévil, M., Kauffman, S. 2012. No entailing laws, but enablement in the evolution of the biosphere. arXiv:1201.2069 [q-bio.OT]. http://arxiv.org/abs/1201.2069.

Longo, G., Montévil, M.. 2011. From physics to biology by extending criticality and symmetry breakings. $J$. Prog. Biophys. Mol. Bio., 106(2):340 -347. Systems Biology and Cancer.

Lurie, J. 2009. Higher Topos Theory. Princeton University Press. ISBN 978-0-691-14049-0.

Mazza, R. 2009. Introduction to Information Visualizaion. Springer. ISBN: 978-1848002180.

MacLane, S. 1950. Duality for groups. Bull. Amer. Math. Soc. 56(6):485-516. http://projecteuclid.org/euclid.bams/1183515045.

McCulloch, W.S. 1945. A heterarchy of values determined by the topology of nervous nets. The bulletin of mathematical biophysics, 7(2): 89-93.

Matsuno, K. 2015. On the Physics of the Emergence of Sensorimotor Control in the Absence of the Brain. $J$. Prog. Biophys Mol Bio. 119(2). Special Theme Issue on Integral Biomathics: Life Sciences, Mathematics, and Phenomenological Philosophy. Elsevier. ISSN: 0079-6107. (in print)

Matsuno, K. 2013. Making Biological Theory More Down to Earth. J. Prog. Biophys Mol Bio, 113(1): 127140: 46-56. Special Theme Issue on Integral Biomathics: Can Biology Create a Profoundly New Mathematics and Computation? Elsevier. ISSN: 0079-6107.

Matsuno, K. 2012. Time in Biology as a Marker of the Class Identity of Molecules. In: Integral Biomathics: Tracing the Road to Reality, Proc. of iBioMath 2011, Paris and ACIB '11, Stirling UK, P. L. Simeonov, L. S. Smith, A. C. Ehresmann (Eds.), Springer, ISBN-10: 3642281109; ISBN-13: 978-3642281105. 269-278.

Matsuno, K. 1998. Space-Time Framework of Internal Measurement. In: Computing Anticipatory Systems, AIP Conference Proceedings 437, edited by D. M. Dubois, 101-15. Woodbury, NY: American Institute of Physics.

Matsuno, K. 1996. Internalist Stance and the Physics of Information. BioSystems 38, 111-118.

Matsuno, K., Salthe, S. N. 2002. The origin and development of time. International Journal of General Systems. 31(4): 377-393.

Murfet, D. 2006. Abelian Categories. http://therisingsea.org/notes/AbelianCategories.pdf.

Nakajima, T. 2015. Biologically inspired information theory: Adaptation through construction of external reality models by living. J. Prog. Biophys Mol Bio. 119(2). Special Theme Issue on Integral Biomathics: Life Sciences, Mathematics, and Phenomenological Philosophy. Elsevier. ISSN: 0079-6107. (in print)

Peirce, C.S., 1869. Grounds of the validity of the laws of logic. In: Hauser, N., Kloesel, C.J.W. (Eds.), The Essential Peirce. Selected Philosophical Writings, vol. 1 (1867-1893). Indiana University Press (1992). ISBN-10: 0253207215; ISBN-13: 978-0253207210.

Randell, R. Ruddle, R.A., Thomas, R.G., Mello-Thoms, C., Treanor, D. 2014. Diagnosis of major cancer resection specimens with virtual slides: impact of a novel digital pathology workstation. Hum Pathol. 45(10):2101-6. doi: 10.1016/j.humpath.2014.06.017.

Root-Bernstein, R. S. 2012. Processes and Problems That May Define the New BioMathematics Field. In: Integral Biomathics: Tracing the Road to Reality, Proc. of iBioMath 2011, Paris and ACIB '11, Stirling UK, P. L. Simeonov, L. S. Smith, A. C. Ehresmann (Eds.), Springer-Verlag, Heidelberg, ISBN-10: 3642281109; ISBN-13: 978-3642281105.

Rosen S. M. 2015. Why Natural Science Needs Phenomenological Philosophy. J. Prog. Biophys. Mol. Bio. 119(2). Special Theme Issue on Integral Biomathics: Life Sciences, Mathematics, and Phenomenological Philosophy. Elsevier. ISSN: 0079-6107. (in print)

Rossi, A. 2011. Renè Thom: Forms, Catastrophes and Complexity. Logic and Philosophy of Science. IX(1):95-101. http://www2.units.it/episteme/L\&PS Vol9No1/L\&PS Vol9No1 2011 08 Rossi.pdf.

Rudolph, L. 2014. Qualitative Mathematics for the Social Sciences: Mathematical Models for Research on Cultural Dynamics. Routledge, ISBN-10: 1138808520; ISBN-13: 978-1138808522. 
Sacks, E. 1985. Qualitative Mathematical Reasoning. Proc. IJCAI-85. http://www.ijcai.org/Past\%20Proceedings/IJCAI-85-VOL1/PDF/024.pdf.

Schroeder, M. J. 2014. Computing as Dynamics of Information: Classification of Geometric Dynamical Information Systems Based on Properties of Closure Spaces. In: Akihiro Yamamura (Ed.), RIMS Kokyuroku, Algebra and Computer Science, Research Institute for Mathematical Sciences, Kyoto University, Kyoto, No. 1873,126-134.

Schroeder, M. J. 2013a. From Proactive to Interactive Theory of Computation. In: M. Bishop and Y. J. Erden (Eds.): The $6^{\text {th }}$ AISB Symposium on Computing and Philosophy: The Scandal of Computation - What is Computation? The Society for the Study of Artificial Intelligence and the Simulation of Behaviour, 4751.

Schroeder, M. J. 2013b. Dualism of Selective and Structural Manifestations of Information in Modelling of Information Dynamics. In: G. Dodig-Crnkovic, R. Giovagnoli (Eds.) Computing Nature, SAPERE 7 , Springer, Berlin. 125-137.

Signer, W., Miksch, S., Schumann, H., Tominski, C. 2011. Visualization of Time-Oriented Data. Springer. ISBN 978-0-85729-078-6.

Simeonov, P. L., Gare, A., Rosen, S.M. (Eds.) 2015. Life Sciences, Mathematics, and Phenomenological Philosophy. Special Theme Issue on Integral Biomathics. J. Prog. Biophys Mol Bio, 119(2). Elsevier. ISSN: 0079-6107. (in print)

Simeonov, P. L. 2015. Yet another time about time. Part I: An essay on the phenomenology of physical time. J. Prog. Biophys Mol Bio. 119(2). Special Theme Issue on Integral Biomathics: Life Sciences, Mathematics, and Phenomenological Philosophy. Elsevier. ISSN: 0079-6107. (in print); also in arXiv: http://arxiv.org/abs/1505.05724.

Simeonov, P. L. Gomez-Ramirez, J., Siregar, P. 2013. On Some Recent Insights in Integral Biomathics. J. Prog. Biophys Mol Bio, 113(1): 216-228. Special Theme Issue on Integral Biomathics: Can Biology Create a Profoundly New Mathematics and Computation? Elsevier. ISSN: 0079-6107. DOI:10.1016/j.pbiomolbio.2013.06.001. also in: arXiv.org, http://arxiv.org/abs/1306.2843.

Simeonov, P. L., Brezina, E., Cottam, Ehresmann, A. C., Gare, A., Goranson, T., Gomez-Ramirez, J., Josephson, B. D., Marchal, B., Matsuno, K., Root-Bernstein, R. S., Rössler, O. E., Salthe, Schroeder, M., S. N., Seaman, Siregar, P., B., Smith, L. S. 2012. Stepping Beyond the Newtonian Paradigm in Biology. Towards an Integrable Computational Model of Life: Accelerating Discovery in the Biological Foundations of Science. INBIOSA White Paper. In: Integral Biomathics: Tracing the Road to Reality, Proc. of iBioMath 2011, Paris and ACIB '11, Stirling UK, P. L. Simeonov, L. S. Smith, A. C. Ehresmann (Eds.), Springer, ISBN-10: 3642281109; ISBN-13: 978-3642281105.

Simeonov, P. L. 2010. Integral Biomathics: A Post-Newtonian View into the Logos of Bios. J. Prog. Biophys Mol Bio, 102(2/3): 85-121. Elsevier, ISSN:0079-6107, DOI: 10.1016/j.pbiomolbio.2010.01.005. http://dx.doi.org/10.1016/j.pbiomolbio.2010.01.005.

Simeonov, P. L. 2002. The Wandering Logic Intelligence. A Hyperactive Approach to Network Evolution and Its Application to Adaptive Mobile Multimedia Communications. Technische Universität Ilmenau, Fakultät für Informatik und Automatisierung, http://d-nb.info/974936766. OCLC WorldCat Number: 76757065.

Smith, W. R. 1983. Qualitative Mathematical Models of Endocrine Systems. Am. J. Physiol. 245(4):473-7. http://www.ncbi.nlm.nih.gov/pubmed/6353946.

Smolin, L. 2006. The Trouble With Physics: The Rise of String Theory, The Fall of a Science, and What Comes Next. Houghton Mifflin Co. ISBN-10: 0-618-55105-0; ISBN-13: 978-0-618-55105-7.

Sober, 2000. Philosophy of Biology. Westview Press/Oxford University Press. ISBN-10: 0813391261; ISBN13: 978-0813391267.

Thom, R. 1977. Structural Stability, Catastrophe Theory and Applied Mathematics. SIAM Review, 19(2): 189201.

Varela, F.J. 1999. The Specious Present: A Neurophenomenology of Time Consciousness. In: J. Petitot, F.J. Varela, J.-M. Roy and B. Pachoud (eds), Naturalizing Phenomenology: Issues in Contemporary Phenomenology and Cognitive Science. Stanford, CA: Stanford University Press. ISBN-10: 0804736103; ISBN-13: 978-0804736107. 166-314.

von Goldammer, E. Joachim, P., Newbury, J. 2003. Heterarchy - Hierarchy: Two complementary categories of description. http://www.vordenker.de/heterarchy/a heterarchy-e.pdf. Accessed on 09.09.2015. 
Vrobel, S. 2015. A New Kind of Relativity: Compensated Delays as Phenomenal Blind Spots. J. Prog. Biophys Mol Bio, 119(2). Special Theme Issue on Integral Biomathics: Life Sciences, Mathematics, and Phenomenological Philosophy. Elsevier. ISSN: 0079-6107. (in print)

Vrobel, S. 2013. Measuring the temporal extension of the Now. J. Prog. Biophys Mol Bio, 113(1):92-96. Special Theme Issue on Integral Biomathics: Can Biology Create a Profoundly New Mathematics and Computation? Elsevier. ISSN: 0079-6107. DOI: 10.1016/j.pbiomolbio.2013.06.001.92-96.

Vvedensky, D.D., Chang, T.S. 1982. Operator expansions for critical dynamics. Phys. Lett. A 90(9): 459-461. Elsevier doi:10.1016/0375-9601(82)90396-6.

Ware, C. 2013. Information Visualization. Elsevier. ISBN 978-0-12-381464-7.

Zaichick, S. V., Bohannon, K. P., Hughes, A., Sollars, P. J., Pickard, G. E., Smith, G. A. The Herpesvirus VP1/2 Protein Is an Effector of Dynein-Mediated Capsid Transport and Neuroinvasion. Cell Host \& Microbe, 2013; 13 (2): 193 DOI: 10.1016/j.chom.2013.01.009.

Zhang, Q., Segall, R. S., Cao, M. 2011. Visual Analytics and Interactive Technologies: Data, Text and Web Mining Applications. Information Science Reference. ISBN 978-1-60960-102-7. 